\title{
AUTOAVALIAÇÃO E AUTOATRIBUIÇÃO DE NOTAS: REFLEXÕES ACERCA DA IMPLEMENTAÇÃO DE UMA PRÁTICA AUTOAVALIATIVA E SUA CAPACIDADE DE PROMOVER A AUTOGESTÃO DA APRENDIZAGEM ${ }^{1}$
}

\begin{abstract}
SELF-ASSESSMENT AND SELF-ATTRIBUTION OF NOTES: REFLECTIONS ABOUT THE IMPLEMENTATION OF A PRACTICAL AUTOAVALIATIVA AND YOUR ABILITY TO PROMOTE SELF-MANAGEMENT OF LEARNING
\end{abstract}

\author{
Andressa Cristina Molinar ${ }^{2}$ \\ Liliam Cristina Marins Prieto $^{3}$
}

RESUMO: Neste estudo, procura-se investigar a relação entre a autoatribuição de notas e o processo autoavaliativo em um instrumento elaborado e aplicado pela professora de uma das disciplinas ministradas em uma turma da pósgraduação em "Formação de professores em Língua Materna e Língua Estrangeira- Inglês" de uma Universidade Paranaense. O objetivo da disciplina era promover a formação continuada de professores reflexivos voltados para a pesquisa. Como objetivo específico, pretende-se analisar o instrumento autoavaliativo como uma forma de promover o processo de "aprender a aprender" por meio de reflexões e da projeção de novos objetivos para a autogestão da aprendizagem. A fim de contribuir para as discussões do processo avaliativo quanto à formação de professores em língua Inglesa, partiu-se da concepção de autoavaliação como um processo viável de promoção da autorregulação da aprendizagem, no qual há a corresponsabilização desse processo pelo aluno e o monitoramento do professor para que o discente se torne um sujeito autônomo e responsável. A análise dos dados revela um desvio pelos alunos do verdadeiro sentido do instrumento autoavaliativo, os quais parecem priorizar a autoatribuição de nota. Pode-se verificar, assim, a necessidade de implementação de atividades autoavaliativas que possibilitem a superação de dificuldades, provocando mudanças no agir do aluno de forma que uma aprendizagem significativa ocorra. Nesse sentido, este estudo se fundamentará principalmente nos pressupostos teóricos de Alvarenga (2002); Costa (2009); Libâneo (2008); Luckesi (2205); Soares (2007); Souza (2004) e Harres (2002).

PALAVRAS-CHAVE: Autoavaliação, Autoatribuição de notas, Autonomia.

ABSTRACT: In this study, we seek to investigate the relationship between the self-attribution of notes and self-assessment in a process developed and implemented by the teacher of one of the subjects taught in a class of graduate studies in "Teacher Training in Maternal and English - Language Foreign

\footnotetext{
${ }^{1}$ Trabalho de conclusão do Curso de Especialização Em Formação de professor de Língua Materna e Língua Estrangeira: práticas reflexivas, metodológicas e tradutórias, Universidade Estadual de Maringá, Maringá, orientado pela professora Ms. Líliam Cristina Marins Prieto..

${ }^{2}$ Especialista pela Universidade Estadual de Maringá. E-mail: dessinha_molinari@hotmail.com

${ }^{3}$ Doutoranda em Letras /UEM e docente efetiva do Departamento de Letras Modernas da Universidade Estadual de Maringá. E-mail: liliamchris@hotmail.com>
} 
Language tool" a Paranaense University. The objective of the course was to promote the continued education of reflective teachers to research-focused. Specific objective, we intend to analyze the self-assessment instrument as a way to promote the process of " learning to learn " through reflection and projection of new goals for self-management of learning . In order to contribute to discussions of the evaluation process as the training of teachers in the English language, we started with the concept of self-assessment as a viable process of promoting self-regulation of learning, in which there is coresponsibility of this process by monitoring student and teacher for the student to become an independent and responsible person. Data analysis reveals a deviation by the students of the true meaning of self-assessment instrument, which seem to prioritize the self-attribution of note. One can thus verify autoavaliativas need to implement activities that allow overcoming difficulties, causing changes in the student's act so that meaningful learning occurs. Thus, this study will build mainly on theoretical assumptions Alvarenga ( 2002), Costa (2009 ) ; Libâneo (2008 ) ; Luckesi ( 2205 ), Smith (2007) and Souza (2004 ) and Harres (2002).

KEYWORDS: Self-assessment, Self-attribution of notes, Autonomy.

\section{Introdução}

A inspiração para a pesquisa aqui relatada surgiu principalmente a partir da necessidade de investigar como promover a autonomia e a autogestão da aprendizagem em sala de aula. Esse questionamento surgiu no contato com leituras acerca do assunto, as quais suscitaram dúvidas devido à dificuldade encontrada em identificar quais práticas avaliativas seriam passíveis de formar sujeitos críticos e reflexivos. Pretendemos, assim, analisar a relação entre a autoatribuição de notas e o processo autoavaliativo e a capacidade desse em promover a autogestão da aprendizagem. Nesse momento, a pesquisa vem como um meio para proporcionar esse processo de reflexão e conhecimento.

Avaliar a aprendizagem foi e continua sendo um desafio significativo aos educadores, sendo muitas vezes rotulada como autoritária e controladora do saber. Porém, torna-se necessário debater sobre a avaliação educacional para que mudanças sejam realizadas e para que não fiquemos apenas na falácia de que avaliar é "ruim". Entre os vários conceitos do termo avaliação, Costa (2009) define que avaliar é questionar: a) quem é o aluno que se diz perdido, b) qual sua necessidade, c) como esse aluno tem evoluído nas tarefas e nos trabalhos, e d) o que se tem feito para ajudá-lo a superar suas dificuldades. A resposta a 
esses questionamentos é início de uma orientação educacional eficaz que envolve alunos, professores e gestores da educação.

Em relação ao papel do professor, acredita-se que muitos têm como objetivo final na hora de avaliar apenas averiguar se o aluno reteve o que foi ensinado e, em muitas ocasiões, não é realizado um trabalho posterior com o intuito de auxiliar esse aluno. Outros utilizam o instrumento avaliativo como forma de ameaça, não um castigo físico, como se fazia há algum tempo, mas um castigo psicológico, propondo questões e tarefas que não foram ensinadas ou que estão além do nível cognitivo e do tipo de raciocínio corriqueiramente trabalhados em sala.

Associada a um ensino diferenciado, a avaliação formativa, por sua vez, compromete-se com o diagnóstico, compreensão e superação das dificuldades de aprendizagem. Para Zaballa (1998), isso permitiria ao professor conhecer e entender as necessidades do aluno e, por isso, o acompanhamento realizado por meio dessa modalidade de avaliação propicia ao professor um agir reflexivo sobre sua prática, uma vez que ele tem a possibilidade de rever o que foi aprendido e propor mudanças. Acompanhar, nesse contexto, refere-se à forma de se observar a evolução do processo educacional em parceria com o aluno, partindo do cotidiano de sala de aula como o primeiro passo.

Ao darmos enfoque à avaliação, almejamos, portanto, contribuir com o processo de formação do professor de Língua estrangeira, uma vez que a divulgação dessas ideias, bem como a discussão acerca do assunto, tem sido foco na academia. Todavia, ainda é preciso proporcionar o desenvolvimento do processo reflexivo como um efeito da reestruturação das práticas de avaliação. Este trabalho propõe, partindo da definição de avaliação formativa como uma investigação dos diferentes momentos da aprendizagem, realizar uma pesquisa de cunho qualitativo, pois demandou recolher os dados em ambiente natural para melhor apreender os aspectos concernentes ao objeto investigado, preservando-se, tanto quanto possível, a perspectiva dos participantes ao responderem às atividades autoavaliativas (BOGDAN; BICKLEN, 1994).

Nessa perspectiva, o objetivo geral deste estudo é investigar a relação entre a autoatribuição de notas e o processo autoavaliativo em um instrumento elaborado e aplicado pela professora de uma das disciplinas ministradas em 
uma das turmas da pós-graduação em "Formação de professores em Língua Materna e Língua Estrangeira- Inglês" de uma Universidade Paranaense. $O$ objetivo da disciplina era promover a formação continuada de professores reflexivos voltados para a pesquisa. Como objetivo específico, pretende-se analisar o instrumento autoavaliativo como uma forma de promover o processo de "aprender a aprender" por meio de reflexões e da projeção de novos objetivos para a autogestão da aprendizagem. É importante ressaltar que a área em questão foi apenas um pano de fundo para tratar da questão da autoavaliação e da autoatribuição de notas.

\section{Avaliação Formativa como uma prática transformadora}

Ao retomar, mesmo que brevemente, a trajetória da avaliação da aprendizagem, parece que seu exercício esteve associado à ideia de diagnosticar, qualificar e classificar, ou seja, a verificar a retenção de informação pelos alunos e repercutir em notas que traduzem o qualitativo de acertos (ALVARENGA, 2002; ALVAREZ MÉNDEZ, 2002; CARDINET, 2006, DEPRESBITERIS, 2009; FERNANDES, 2009; HOFFMANN, 2010; LUCKESI, 1995, 2011; PERRENOUD, 1999). Ainda nos dias atuais, a avaliação é concebida, muitas vezes, como instrumento de verificação de erros e acertos e também de observação do sucesso ou insucesso na aprendizagem, superação ou não de dificuldades por parte dos aprendizes e obtenção ou não de novos conhecimentos por eles. A definição pode, ainda, estender-se para indicar o bom ou mau desempenho do professor em suas aulas.

No despacho Normativo $\mathrm{N}^{\circ} 1 / 2005$ de 5 de Janeiro ${ }^{4}$, a avaliação é concebida como um instrumento de regulação da aprendizagem que visa dar suporte e garantir o sucesso de todos os alunos, permitindo o ajuste de projetos curriculares em conformidade com as suas necessidades. $O$ artigo 19 desse mesmo documento define a avaliação formativa como principal modalidade de avaliação, com caráter contínuo e sistemático, que objetiva

\footnotetext{
${ }^{4}$ Ato regulamentar proferido em casos individuais, e posteriormente aplicado ao geral, e vigorado como norma, sendo assegurada sua publicidade pela Constituição Federal.
} 
regular o ensino e a aprendizagem através da utilização dos mais diversos instrumentos de obtenção de informação. Além disso, outro compromisso está vinculado à avaliação da aprendizagem: a promoção do desenvolvimento das aprendizagens e competências que permitem ao aluno rever e melhorar seu processo de aprendizagem.

Para Méndez (2004, p. 78), a avaliação da aprendizagem, quando implementada em perspectiva formativa, tem, nas informações obtidas, "[...] ponto de referência para a ação didática, fornecendo informação valiosa sobre os progressos reais de quem está aprendendo [...] as dificuldades que encontra e o modo de superá-las". Ao avaliar para promover a aprendizagem, o professor compromete-se com a proposição de intervenções criticamente informadas. Ao fazê-lo, não pode centrar-se nas ações de ensino, mas precisa privilegiar o engajamento do aluno na gestão da própria aprendizagem.

Fernandes (2011, p. 20-21), por sua vez, registra que a avaliação da aprendizagem constitui um processo, deliberado e sistemático, destinado a prover o professor de informações relativas "[...] ao que os alunos sabem e são capazes de fazer em uma dada situação. [...] Ou seja, ações que contribuam decisivamente para que os alunos ultrapassem eventuais dificuldades e aprendam com mais gosto e autonomia". Ele completa remetendo à corresponsabilização do aluno com a própria aprendizagem ao enfatizar a importância dessas ações quando contribuem para o desenvolvimento dos processos autoavaliativos e autorregulatórios.

Essa modalidade de avaliação, portanto, se encaixa como um procedimento viável para a aprendizagem, uma vez que possibilita ao aluno tomar para si a responsabilidade de seu aprendizado por meio do monitoramento e regulação dos processos autoavaliativos. No entanto, esse processo é complexo, pois o aluno, em muitos casos, não tem iniciativa necessária para tal. Por essa razão, o papel do professor é de extrema importância como mediador e incentivador nesse processo. Assim, para que a autorregulação da aprendizagem se efetive, ou seja, para que o próprio aluno monitore a sua aprendizagem, é latente que ele observe seu próprio desenvolvimento por meio do monitoramento constante. 


\section{Autoavaliação versus autoatribuição de notas: algumas considerações}

De acordo com Costa (2009), a autoavaliação é um dispositivo regulador do processo de ensino e aprendizagem, sendo que, nela, o aluno deve ter voz ativa e intervir no processo. Koutsoupidou (2010) define autoavaliação:

(...) como um meio de avaliação formativa que incide sobre os sentimentos e crenças dos professores e crenças sobre a sua capacidade de ensino e eficácia em lidar com uma variedade de situações de sala de aula e na escola. Ela serve também como um recurso para alunos e professores refletirem sobre seu trabalho e descobrir seus pontos fortes e fracos" (KOUTSOUPIDOU, 2010, p. 105). ${ }^{5}$

Isso significa que o aluno deve ser capaz de, sozinho, reconhecer as falhas e solucionar seus erros. Nessa perspectiva, "a implementação de uma avaliação processual e formativa e não sancionadora orientada para a responsabilidade pela própria aprendizagem é fundamental" (HARRES, 2002, apud HARRES, 2003, p. 2). Da mesma forma, Kasanen e Räty (2002) afirmam que a autoavaliação é parte essencial do processo de aprender a aprender, cujo objetivo é de proporcionar motivação, e guiar e ajudar o aluno em situações futuras de avaliação externa. Por isso, deve-se propiciar aos discentes situações de aprendizagem em que eles possam treinar e desenvolver suas habilidades em autoavaliação, assim como obter um parecer sobre suas avaliações.

Um ponto a ser salientado no processo de autoavaliação é a autoatribuição de notas na aprendizagem. Esta distorce o real significado da prática autoavaliativa, uma vez que, para não se prejudicar, o aluno não será verdadeiro no momento de atribuir-se um valor. Preocupado em não alcançar a média necessária para a aprovação, o aluno pode dispor-se a manipular valores, pois tem na reprovação uma ameaça que o impede de informar as

\footnotetext{
5 Tradução da pesquisadora. "(...) as a formative means of assessment that focuses on teachers' own feelings and beliefs about their teaching ability and efficacy in dealing with a variety of school and classroom situations. [It also] means for students and teachers to reflect on their work and discover their strengths and weaknesses". (KOUTSOUPIDOU, 2010, p. 105).
} 
suas dificuldades. Não se pode negar que o aluno é cerceado por regras acadêmicas e isso interfere no processo de autoatribuição de notas, fazendo com que os alunos não percebam o verdadeiro significado da aprendizagem e a permutem pelas notas necessárias à conquista do direito de ir para a etapa seguinte. Isso porque a autoatribuição de notas é vista pelos alunos como uma oportunidade de melhorar a média, que, por consequência, não os levam a perceber que a nota nada contribui para o aprimoramento da aprendizagem, como afirmam Kasanen e Räty (2002).

Vale salientar, ainda, que alguns pontos são essenciais para a efetivação do processo autoavaliativo, estes são: identificar os objetivos, reconhecer os pontos fortes e as dificuldades, reconhecer o processo reflexivo, projetar novos objetivos para a autorregulação da aprendizagem, executá-los e realizar constante monitoramento. Estes aspectos oportunizam a corresponsabilização do aprender, garantindo maior persistência na aprendizagem pelo aluno ao sair do ambiente escolar. Soares (2007) assevera que, na autorregulação, o aluno precisa ficar atento às informações que são transmitidas no processo de aprendizagem, interpretá-las e integrá-las, para que, assim, melhores resultados sejam alcançados. E, para tal, apenas o exercício contínuo levará à prática eficiente em relação à aprendizagem, o que aponta novamente para a importância do papel do professor para orientá-lo.

Nessa mesma direção, as Diretrizes Curriculares Nacionais (DCN) (BRASIL, 1999) explicam que o processo de avaliar contribui para a percepção das dificuldades do aluno, tendo em vista mudanças que colaborem para a concretização e potencialização da aprendizagem. Nessa perspectiva, a avaliação da aprendizagem fundamentada na LDB. 9394 / 96 objetiva propiciar ao aluno a percepção da dimensão de onde se encontra sua aprendizagem e que a escola seja capaz de "construir uma avaliação com critérios de entendimento reflexivo, conectado, compartilhado e autonomizador [...] que nos permita formar cidadãos conscientes, críticos, criativos, solidários e autônomos" (ALVES, 2003 p. 24). Vale salientar que o desenvolvimento dessa autonomia está profundamente vinculado à prática autoavaliativa.

É essencial que o aluno passe por situações que irão propiciar o desenvolvimento de sua autonomia e responsabilidade. Para tanto, faz-se 
necessária a introdução de mudanças nas salas de aulas e na cultura de avaliação praticada nas escolas, pois é preciso romper com o resultado de um aprendizado refletido em números que servem para classificar, diferenciar e discriminar os supostos "bons alunos" dos "ruins". O processo gradativo de mudanças nos documentos oficiais sugere a necessidade de perceber o aluno como o foco do processo educacional, inclusive no âmbito da avaliação da aprendizagem. Do aluno, espera-se que saiba quais os objetivos a serem alcançados, as estratégias possíveis e quais recursos utilizar para que, no momento da aprendizagem, ele opte por aquelas que lhe são mais favoráveis. Além disso, espera-se dele o desenvolvimento de uma "metodologia de aprender a aprender [baseada na] na construção de conceitos a partir de ideias anteriores" (SOARES, 2007 p. 23). Quanto ao professor, espera-se que ele saiba guiar, explicitando os objetivos a serem alcançados, e ouvir o aluno, intervindo em sua mudança e em seu agir. Mais ainda, o professor deve propiciar situações avaliativas de interação entre alunos e professores, alunos e alunos, e aluno e material didático. Nesse sentido, o processo deve ter maior ênfase que o resultado da aprendizagem, pois é no processo que 0 conhecimento do aluno passa por alterações.

Alvarenga (2002, p. 57) corrobora tal posição ao afirmar que a avaliação precisa favorecer o desenvolvimento do aluno em todo seu processo de escolarização e que esta precisa ter como foco a "solução das dificuldades detectadas na aquisição e na construção do conhecimento". Avaliar é ultrapassar as "leituras" que se fazem dos alunos e buscar leituras positivas, pois, se há a necessidade de formar alunos críticos, capazes de pensar por si, de questionar, ou seja, de serem agentes, não há como encaixá-los em critérios rígidos de avaliação. A partir desse momento, o aluno se tornará independente e confiante para aprender seguindo seus próprios roteiros.

\section{Reflexões sobre uma prática autoavaliativa realizada com alunos de um curso de Especialização}

Gimenez (2009) afirma que uma das causas para que não exista uma sala de aula centrada na autonomia é o despreparo de alguns professores e 
suas insatisfações com relação à profissão. Segundo a autora, a construção da autonomia no processo de ensino e aprendizagem deve ser realizada na Universidade, por isso, é necessário dar oportunidade para o aluno-professor refletir sobre sua aprendizagem e sobre sua prática enquanto formador.

A pretensão de estabelecer um paralelo entre os eventuais desdobramentos da autoavaliação e da autoatribuição de notas entre professores em formação em nível de especialização delineou o objetivo no transcorrer deste estudo: analisar a relação entre a autoatribuição de notas e o processo autoavaliativo e a capacidade desse em promover a autogestão da aprendizagem. A coleta de dados aconteceu em março e abril de 2012 com a participação de 27 professores/estudantes. Foi aplicado um instrumento avaliativo pela professora de uma das disciplinas do curso, que tinha por objetivo enfatizar a formação de professores reflexivos por meio de discussões relativas ao papel das crenças e identidade do professor de línguas. As atividades avaliativas abarcavam tarefas regulares ao longo da disciplina: um trabalho criativo, um trabalho final de disciplina em formato de artigo e uma autoavaliação por critérios. Em relação ao instrumento autoavaliativo, os alunos poderiam escolher quatro critérios para se autoavaliarem, atribuindo pontuações apropriadas a cada item, com valor de um ponto. Após a escolha dos critérios e respectiva pontuação, a professora requisitou que os alunos apresentassem justificativas, em forma de texto escrito.

Como o professor tem papel fundamental para intervir no desenvolvimento do aluno, é preciso que professor e aluno compreendam as causas e ações do processo de ensino. Da mesma forma, para que a autoavaliação seja um instrumento legítimo, é necessário que o aluno conheça em que nível está sua aprendizagem e compare o que é real e o que é desejado, mas, o mais importante é que este instrumento não seja usado apenas para se obter uma nota. Diante de tal pressuposto, nota-se que, no processo autoavaliativo investigado, nota e reflexão foram exigidos. Entretanto, não se pode negar que a atribuição de notas pode dificultar e impossibilitar a reflexão e o comprometimento com a superação, pois pode ser apenas uma coleção de números.

Além disso, a autoatribuição de notas apresenta algumas fragilidades, 
como propiciar a estagnação do conhecimento, pois, ao se atribuir uma nota, o aluno descompromete-se com a aprendizagem e o aprimoramento. Quando os números são suficientes à aprovação, não é mais preciso que o aluno dediquese com afinco à busca da nota para diminuir o prejuízo, pois não é mais necessário reduzir as distâncias entre o real e o desejado. Quanto aos dados analisados, como pode ser observado no quadro 1 , apesar de a grande maioria dos alunos apontar suas dificuldades no momento da avaliação, nenhum deles se prejudicou. Entre as notas atribuídas pelos participantes, nenhuma foi inferior a média, pelo contrário, foram todas superiores, como pode ser observado no quadro abaixo:

Quadro 1 - Notas autoatribuídas em atividade autoavaliativa

\begin{tabular}{|c|c|}
\hline $\begin{array}{c}\text { Valor } \\
\text { autoatribuído na } \\
\text { autoavaliação }\end{array}$ & $\begin{array}{c}\text { Quantidade de } \\
\text { alunos por nota }\end{array}$ \\
\hline 0,75 & 5 \\
\hline 0,76 & 1 \\
\hline 0.80 & 3 \\
\hline 0,85 & 4 \\
\hline 0,90 & 6 \\
\hline 0,92 & 1 \\
\hline 0,95 & 5 \\
\hline 1,00 & 2 \\
\hline
\end{tabular}

Fonte: Dados de pesquisa.

O peso da nota reduz, quando não retira por completo, a possibilidade de uma resposta verdadeira por parte de muitos dos alunos. Eles não se sentem confortáveis para avaliar a própria aprendizagem, listando as suas deficiências e notificando as suas não aprendizagens. É necessário lembrar 
que, nesse processo, cumpre ao professor contribuir para que os alunos reflitam, percebam o que, quanto e como aprenderam para, em seguida, poderem planificar e empreender ações de superação, em completa independência do alcance ou não de escores.

É importante destacar também que o aluno precisa se sentir confortável para avaliar sua própria aprendizagem e propor mudanças, e o professor é um mediador neste processo, pois quando "contribui para a consciencialização da sua [do aluno] situação escolar e do seu desenvolvimento em termos cognitivos, a co-avaliação possibilita a partilha de saberes e o apoio mútuo " (SOARES, 2007 p. 25).

Quanto às justificativas que apresentam, um dos participantes, por exemplo, afirma que autoavaliar-se é conferir-se uma nota, enquanto esta deveria ser uma atividade que permitiria aos alunos identificar as capacidades e dificuldades, além de instigá-los a pensar e planejar ações interventivas:

Procurei escolher critérios para avaliação nos pontos em que me considero mais forte. Tentei ser o mais honesto possível, comigo mesmo e com os colegas, entretanto, não considero esses critérios como sendo os melhores, apenas pensei que, dessa forma, teria uma avaliação melhor para mim mesmo $(X 16)^{6}$.

O depoimento desse aluno revela uma tentativa de conciliar os seus próprios interesses e necessidades às exigências e possibilidades do instrumento. Ele apenas seleciona os itens nos quais considera haver alcançado maior aprendizagem, deixando de lado aqueles que revelariam as suas fragilidades. Mas são essas dificuldades que precisam ser objeto de reflexão por parte do aluno e são elas que precisam ser informadas ao professor, para que ele, compreendendo-as, intervenha de maneira fundamentada e oportuna.

Santos (2002, p. 2) assevera que "a autoavaliação é um processo de metacognição, entendido como um processo mental interno através do qual o próprio aluno toma consciência dos diferentes momentos e aspectos da sua

6 Daqui em diante, os alunos-sujeitos da pesquisa serão identificados pela letra $X$ e um número, substituindo seus nomes, a fim de resguardar suas respectivas identidades. É importante salientar que não foi realizada uma revisão ortográfica e gramatical nos trechos transcritos. 
atividade cognitiva". Isso significa que a autoavaliação é um olhar observado sobre o que se faz, enquanto se faz, o que poderia justificar, portanto, a falta de segurança do aluno no trecho abaixo, uma vez que ele só se sentiu confortável para realizar a autoavaliação no momento em que percebeu que era parte do processo:

Eu não havia feito minha autoavaliação até o momento, porque não me sentia segura em fazê-la de maneira consciente mais nesse momento já percebo uma segurança que não possuía antes (X19).

É possível estabelecer uma relação de oposição ao que é dito pelo aluno e o real processo cognitivo que necessita ocorrer de forma integrada ao processo autoavaliativo, pois, para produzir o resultado esperado, foi necessário que o aluno se conduzisse a um hábito conscientemente. Por isso, suas inseguranças permeiam todo o discurso construído na autoavaliação.

Ao saber que "a avaliação formativa não pode ser interpretada em termos de classificação ordenada ou de desvios de média" (CARDINET, 1993 p. 119), torna-se necessário que o professor dedique tempo de sua aula para tornar a prática autoavaliativa um hábito e que os alunos passem a ser autorreguladores e autogestores de sua aprendizagem, além de estar em constante processo de reformulação de conhecimento.

Em relação à determinação de objetivos, entre os 27 participantes da pesquisa, apenas 4 explicitaram o que intencionavam atingir no final do processo de aprendizagem. Entre as respostas fornecidas, 3 se destacaram:

Porém, a disciplina foi maravilhosa e me ajudou muito na formação como uma educadora no ensino de língua inglesa (X10).

Meu interesse me levou a esse curso. (...) Passei a gostar dos textos e dos assuntos discutidos em sala, criei expectativas em relação aos assuntos que veio de encontro com questionamentos que eu já me fazia, porém sem respostas (X19).

Inicio minha autoavaliação, ressaltando a relevância desta disciplina no curso de pós-graduação, que tem como propósito melhorar o desempenho profissional do professor de língua estrangeira (X27).

Ao passo que alguns alunos têm claro os objetivos a serem alcançados, a grande maioria não foi capaz de antecipar e situar explicitamente qual seria o 
propósito a ser alcançado ao final da disciplina, apenas cumpriram a tarefa proposta. Acrescente-se a isso o fato de a construção de objetivos expressar a independência na conduta desses alunos quanto às escolhas para a própria aprendizagem, na qual a autonomia exerce papel fundamental. Em relação a esse aspecto, Souza e Boruchovitch (2009) evidenciam que, na avaliação formativa, a aprendizagem é edificada por uma tarefa com objetivos previamente definidos ou negociados, na qual o agir do professor e do aluno devem estar em consonância. Essa perspectiva, igualmente em Holec (1981 apud CAVALARI, 2011), envolve a construção de um sujeito mais autônomo no sentido de ter e manter responsabilidades pelas deliberações relacionadas ao processo de aprendizagem, tendo os objetivos como uma primeira etapa.

Quanto aos critérios escolhidos para o instrumento avaliativo aplicado, pode ser destacada a realização das leituras para discussão em sala com 17\%, a participação com $15 \%$ e a pontualidade com $12 \%$, como pode ser observado na figura abaixo:

Figura 2 - Critérios autoavaliativos

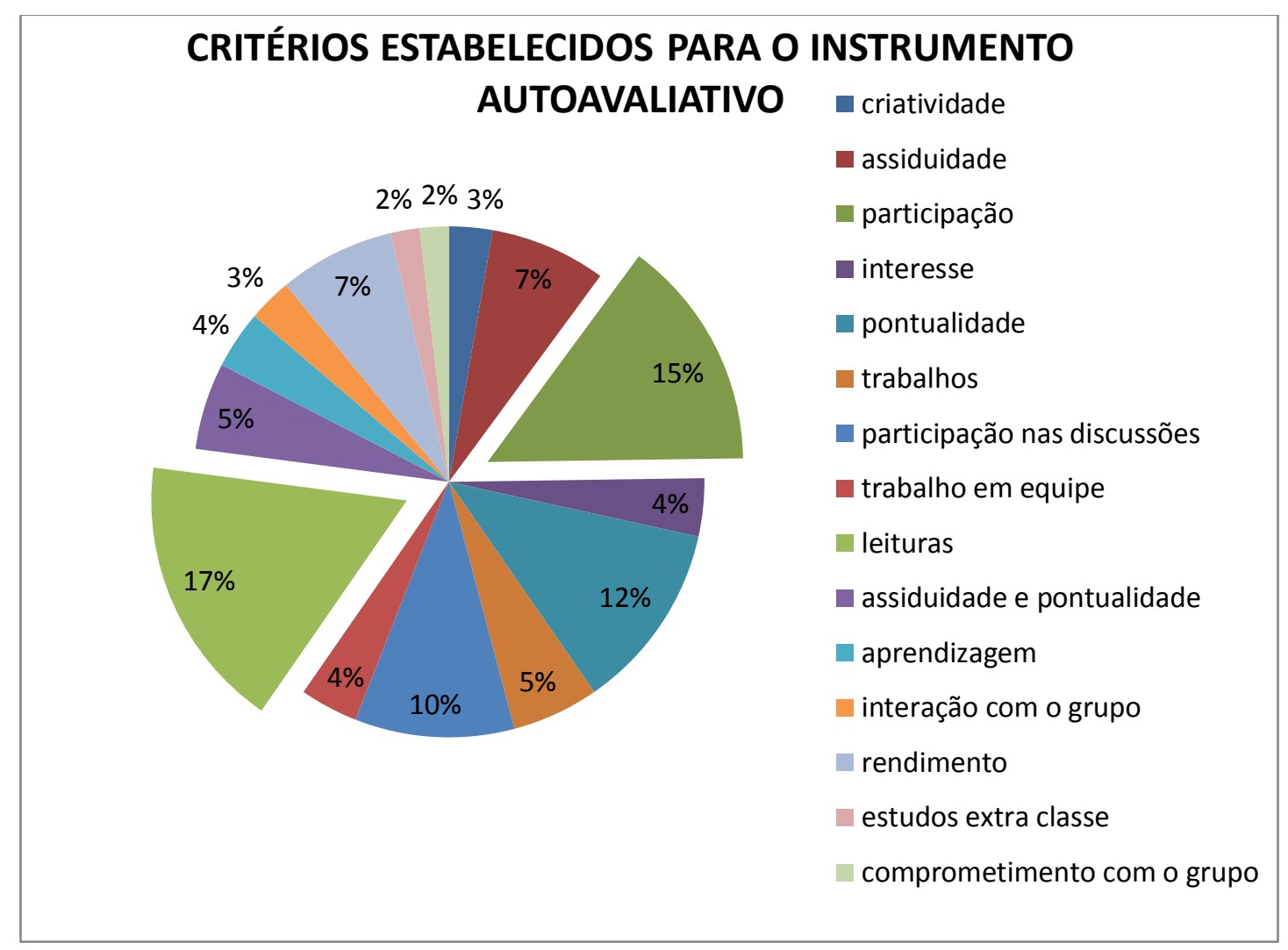


Fonte: Dados de pesquisa.

Além dos critérios destacados no parágrafo anterior, as respostas dos sujeitos ressaltaram critérios relacionados à participação nas discussões em sala, à assiduidade e ao rendimento na disciplina, ou seja, à evolução do aprendizado ao longo dos encontros. Cabe-nos, então, refletir a necessidade desses critérios para balizar a superação de dificuldades de aprendizagens em relação aos objetivos considerados essenciais na disciplina. Os critérios informados para auxiliarem o aluno a realizar uma análise da própria aprendizagem devem favorecer a identificação das dificuldades em relação à apropriação dos conteúdos conceituais, factuais, procedimentais e, também, atitudinais. Mais ainda, os alunos precisam ser incitados a refletir no que farão no momento posterior à avaliação para não cometerem os mesmos erros, superando, assim, as suas dificuldades. Dessa maneira, não é suficiente informar o problema, é fundamental comprometer-se com a sua solução. Conforme Libâneo (2008), os alunos precisam perceber os seus erros, os seus pontos fortes e dificuldades no decurso da aprendizagem, assim como precisam compreender as razões subjacentes aos problemas para conceberem e desenvolverem um plano de ação centrado na superação. O resultado desse processo é a autorregulação da aprendizagem.

Ainda em relação ao aluno, saber as necessidades de aprendizado e reconhecer 0 que precisa ser melhorado é essencial para que o desenvolvimento no processo educacional se consolide. Além disso, reconhecer o que foi aprendido e dar continuidade aos estudos para se aperfeiçoar também é essencial para a formação de um profissional capaz de gerir e monitorar o próprio aprendizado e o de seus alunos. Em relação a esse aspecto, muitos comentários foram tecidos. Ao informar as dificuldades, os participantes apresentam razões e tentam justificar o não fazer, mas não elucidam quais ações pretendem empreender para tentar amenizar os problemas. O sujeito $\mathrm{X} 9$, por exemplo, culpa a "timidez e o medo de falar besteiras" como causa para deixar de "compartilhar as opiniões durante as aulas e os trabalhos em grupo". Já o respondente X5 se escusa de não realizar todas as leituras em decorrência do "excesso de leituras pedidas no curso". Em relação ao mesmo critério, $X 7$ traz para si a responsabilidade de não ler e não 
aprofundar os estudos quando reconhece não haver "organizado o próprio tempo".

Por ser tímida e por medo de falar besteiras deixei várias vezes de compartilhar minhas opiniões. (X9)

Sendo as leituras essenciais e por não conseguir fazer todas antes dos encontros pelo excesso de leituras no curso de graduação, sinto que não consegui apreender da forma que deveria. (X5)

Poderia me comprometer a estudar mais e ainda, ter sido mais pontual às aulas. (X7)

Eu mais pequei me dei uma nota regular devido minhas faltas $\mathrm{e}$ por não ter sido tão pontual como deveria. (X6)

Não tive tanto tempo para a leitura e não fiz uma leitura muito investigadora e profunda do assunto. Creio que o principal motivo foi má organização do tempo livre que dedico ao estudo. (X7)

A organização do tempo, assim como outras dificuldades, podem ser minimizadas ou superadas quando, em decorrência da autoavaliação, o professor promove atividades que impliquem na apropriação de estratégias de aprendizagem por parte do aluno, por exemplo, organizar o tempo, o espaço de estudo e identificar ideias principais em textos são algumas das possibilidades. Quanto aos problemas de assiduidade e pontualidade, não são informadas tentativas no sentido de reduzi-los ou aboli-los. Os participantes utilizam verbos modais para justificar suas ações como possibilidades (que não se concretizaram): "poderia me comprometer e ser mais assídua", "poderia ter sido mais pontual", "não ter sido pontual como deveria". Ao compreender a razão do absenteísmo e da impontualidade, essas questões para a solução das dificuldades não são propostas e, consequentemente, não são respondidas.

Pensamos, então, sobre qual seria o valor de um instrumento autoavaliativo que provoca reflexão, mas apenas uma constatação. Não há razão para se empregar tempo registrando o que não se faz, entendendo as razões subjacentes ao não fazer, pois se identifica o problema, mas não há compromisso para sua superação. Aqueles participantes que, por sua vez, informam o atendimento aos critérios que indicam na atividade autoavaliativa, esclareceram dispor de condições pessoais prévias, porém, que independeram dos objetivos traçados e trabalhados no decurso da disciplina, como as 
amostras a seguir comprovam:

\begin{abstract}
Por ser muito comunicativa, e não sentir vergonha pra falar, participei de muitas discussões. (X5)

Participei da maioria das aulas, assisti e fiz todas as leituras. Fui criativa e até me permito dizer que "mudei" em alguns aspectos depois de entrar em conflito com minhas crenças varias vezes. (X6)

Essas discussões foram muito importantes para o esclarecimento de algumas dúvidas ainda existente após a leitura dos textos e também para troca de experiências e idéias. (X11)
\end{abstract}

Para alguns dos participantes, os conteúdos aprendidos geraram mudanças, como em $\mathrm{X} 6$. Para $\mathrm{X} 11$, os momentos mais significativos foram aqueles nos quais pôde questionar e trocar informações, pois Ihes permitiram esclarecer dúvidas. Mesmo entre aqueles que reportaram haver aprendido e mudado e que destacam as próprias realizações, nada é elucidado em termos de como melhorar. O foco incide somente sobre o passado, sem prospecção. Mas, autoavaliar-se é olhar o passado de forma a planificar o futuro, transformando-o em realidade. Porém, os alunos não conseguem realizar todo esse percurso solitariamente, mas necessitam do auxílio do professor.

Os alunos precisam aprender a refletir acerca de suas realizações e dificuldades, e identificar seus pontos fortes para deles se valerem na superação de seus pontos fracos. Conforme postula Mattos (2002), a reflexão é um elemento favorável e fundamental para realizar transformações, mas não é suficiente. É preciso o estabelecimento e gestão de uma pauta de tarefas contributivas à superação, à aprendizagem e ao desenvolvimento, no intuito de assegurar o cumprimento dos prazos definidos ou de tracejar novos percursos. Perceber isso é o primeiro passo para transformação de condutas, caso se espere essa transformação.

Fica evidente, portanto, a influência que as diferenças de aprendizagem individuais, o conhecimento, as motivações, os empecilhos, entre outros, exercem no processo de aprendizagem. Por isso, é necessário que os alunos saibam quais estratégias e recursos utilizar para que, no momento necessário, eles sejam capazes de optar pela mais favorável. Como declara Cavalari (2011, p. 254), é necessário: 
Definir os conteúdos e as progressões, a organização dos materiais disponíveis, selecionar as estratégias a serem usadas entre aquelas que o aprendiz já conhece, aquela que ele observa outros aprendizes utilizando e aquelas que ele próprio pode inventar (CAVALARI, 2011).

Miccoli (2007), da mesma maneira, destaca o valor da reflexão, porque revela a instalação das dúvidas, das tentativas de entender razões e subsidiar mudanças e transformações. Tomar consciência é perceber elementos antes deixados abandonados, é aceitar a dúvida como natural e desejável e sair das aparências, apropriando-se da essência dos fenômenos e situações. A reflexão, característica da avaliação formativa e do processo autoavaliativo, é essencial para a reconfiguração do conhecimento. Algumas reflexões acerca desse aspecto foram encontradas nas autoavaliações, como pode ser observado nos excertos a seguir:

\begin{abstract}
Acredito ter aprendido muito com a disciplina, principalmente quando paro e reflito sobre o meu dia a dia. Nunca havia utilizado uma parte do meu dia, ou semana para pensar sobre como eu desenvolvo minhas aulas. (X5)

Entendia que havia algo errado por isso procurei ampliar meus conhecimentos através da pós (...). Mesmo difícil é possível ver a mudança. Ficou fácil, pois hoje consigo ver onde errei e reflito sobre. (...) Hoje entendo o que preciso mudar e consigo falar sobre com a certeza de que as leituras me tornaram consciente sobre o papel ser professor. (X8)
\end{abstract}

Em relação à projeção de novos objetivos para a autorregulação da aprendizagem, à execução desses novos objetivos e ao monitoramento dos procedimentos de aprendizagem, nenhum dos respondentes apresenta esta perspectiva. Assim, para que a melhoria da própria aprendizagem aconteça, torna-se necessária a construção de um sistema de pilotagem interna, no qual o aluno dedicará seu tempo, com a ajuda do professor, para elaborar estratégias que facilitarão a (re)elaboração do conhecimento e a construção de sua autonomia.

A autoavaliação e autoatribuição de notas são procedimentos avaliativos distintos e, por isso mesmo, não podem ser concebidos como se os seus objetivos fossem convergentes ou congruentes em algum aspecto. Enquanto $o$ 
primeiro dispensa o segundo e é por ele prejudicado, o segundo retira o foco do primeiro e compromete, quando não impossibilita, a sua consecução.

\section{Algumas considerações}

A análise dos dados expostos na pesquisa ressaltou 0 quanto 0 processo autoavaliativo é essencial para a formação de alunos independentes, autônomos e capazes de reconhecer suas necessidades de aprendizado. A autoavaliação analisada, de maneira ainda preliminar e incipiente, foi capaz de instigar os alunos a refletirem sobre seu processo de aprendizagem e a informarem algumas de suas dificuldades, bem como alguns de seus avanços. Isso se deu nos momentos das justificativas e da escolha dos critérios e dos valores que os alunos se autoatribuíram a partir deles, procedimento esse também previsto no instrumento autoavaliativo.

Para além da reflexão que foi realizada pelos alunos nos momentos de conscientização sobre a própria aprendizagem, houve um atrelamento de valores numéricos ao instrumento, o que faz com que a experiência de autoatribuição de notas seja mais evidente do que a autoavaliação. O medo e a possibilidade de escolha de critérios com os quais se beneficiariam em detrimento de outros que os prejudicariam justificam os valores altos que os sujeitos se autoatribuíram.

Outro ponto a ser salientado é a ausência de subsídios de remediação da aprendizagem ou, até mesmo, a preocupação com o desenvolvimento cognitivo desses alunos por meio de propostas de mudança. Isso porque 0 instrumento é realizado no final de um período e não em um processo no qual o professor possui um tempo para que as habilidades metacognitivas e de pilotagem interna sejam desenvolvidas nos alunos (SANMARTI 2009 apud PUNHAGUI, 2012).

A avaliação, além de ser um instrumento de certificação dos objetivos, precisa se converter em um instrumento diagnóstico com o intuito de promover a progressão na aprendizagem. Os alunos em questão não tiveram a oportunidade de vivenciar atividades que transparecessem a verdadeira função 
da autoavaliação: identificar suas dificuldades para realizar propostas interventivas e, com isso, desenvolver sua autorregulação. Espera-se, contudo, que, futuramente, as barreiras que interferem no processo continuado de aprendizagem desses alunos sejam superadas por meio de práticas centradas no aluno. Além disso, espera-se que este se posicione em face de seu aprendizado, adotando uma conduta reflexiva ao aprender sobre como aprender a partir de uma postura mais autônoma e autorregulada.

\section{Referências bibliográficas}

ALVARENGA, Georfravia Montoza. A avaliação formativa e os conteúdos conceituais: a busca da compreensão. In: ALVARENGA, Georfravia Montoza. (Org. ALVARENGA, Georfravia Montoza). Avaliação: o saber na transformação do fazer. Londrina: Núcleo de Pesquisas em Avaliação Educacional, 2002.

ÁLVAREZ MÉNDEZ, Juan Manuel. Avaliar para conhecer e examinar para excluir. Porto Alegre: Artmed, 2002.

ALVES, M. P. Avaliação de competências: mudar os nomes ou mudar as práticas? Revista Elo Especial, p. 203-211, 2003.

BOGDAN, Robert; BIKLEN, Sari Knopp. Investigação qualitativa em educação: uma introdução à teoria e aos métodos. Porto: Porto Editora, 1994.

BRASIL. Ministério de Educação e Cultura. LDB - Lei no 9394/96, de 20 de dezembro de 1996. Estabelece as diretrizes e bases da Educação Nacional. Brasília: MEC, 1996.

Parâmetros Curriculares Nacionais para o Ensino Médio: Parte I — Bases Legais. Brasília, 1999.

- Ministério da educação. Secretaria de educação básica. Parâmetros nacionais de qualidade para a educação. Ministério da Educação. Secretaria de Educação Básica: Brasília (DF), 2006.

- 2005. DESPACHO NORMATIVO N1/ 2005, Avaliação das aprendizagens dos alunos no ensino básico, Diário da República nํㅜ 3, I SÉRIE $B$, de 5 de Janeiro. Disponível em: http://www.vivaaescola.net/images/docs/dnorma1_2005.pdf Acesso em 31 maio, 2012.

CARDINET, Jean. Avaliar é medir? Rio Tito: Asa, 1993.

COSTA. Manuela. Auto-avaliação - Representações e práticas de professores 
de Línguas estrangeiras. Actas do X Congresso Internacional GalegoPortuguês de Psicopedagogia. Braga: Universidade do Minho, 2009.

CAVALARI, Susy Marques Spatti. A autoavaliação da aprendizagem de inglês como língua estrangeira em um ambiente tandem a distância. RBLA. Belo Horizonte, v. 11, n. 1, p. 247-270, 2011.

DEPRESBITERIS, Léa. Diversificar é preciso... instrumentos e técnicas de avaliação da aprendizagem. São Paulo: Editora SENAC, 2009.

FERNANDES, Domingos. Avaliar para aprender: fundamentos, práticas e políticas. São Paulo: Editora UNESP, 2009.

GIMENEZ, Telma. Ensinar a aprender ou ensinar o que aprendeu? In: LIMA, Diógenes Cândido de. (Org.). Ensino e aprendizagem de língua inglesa: conversas com especialistas. São Paulo: Parábola, 2009, p. 107-112.

HARRES, João Batista Siqueira. Avaliação não classificatória e auto-avaliação: uma estratégia para o desenvolvimento profissional de futuros professores. Actas del XX Encuentros de Didáctica de las Ciencias Experimentales, La Laguna, p. 707-715, 2002.

Desvinculação entre avaliação e atribuição de nota: análise de um caso no ensino de física para futuros professores. Ensaio: Pesquisa em Educação em Ciências, Belo Horizonte, v. 5, n. 1, p. 4, 2003.

HOFFMANN, Jussara. Avaliar para promover: as setas do caminho. Porto Alegre: Mediação, 2001.

2010.

Avaliar: respeitar primeiro e educar depois. Porto Alegre: Mediação

KASANEN, Kati; RÄTY, Hannu. You be sure now to be honest in your assessment: Teaching and learning self-assessment. Finland, Kluwer: University of Juensuu, 2002.

KOUTSOUPIDOU, Theano. Self-Assessment in Generalist Preservice Kindergarten Teachers' Education: Insights on Training, Ability, Environments, and Policies. Rodes, Greece: University of the Aegean, 2010.

LIBÂNEO, José Carlos. Didática. 28. ed. São Paulo: Cortez, 2008.

LUCKESI, Cipriano. Avaliação da aprendizagem escolar. 20. ed. São Paulo: Cortez. 2005.

Avaliação da aprendizagem: componente do ato pedagógico. São Paulo: Cortez, 2011.

MICCOLI, L. Autonomia na aprendizagem de língua estrangeira. In: PAIVA, Vera Lúcia Menezes de Oliveira. (Org.). Práticas de ensino e aprendizagem de inglês com foco na autonomia. 2. ed. São Paulo: Pontes, 2007, p. 31-50. 
PERRENOUD, Philippe. Avaliação: da excelência à regulação das aprendizagens - entre duas lógicas. Porto Alegre: Artmed, 2009.

SANTOS, L. Auto-avaliação regulada. Porquê, o quê e como? Ministério da Educação, 2002. Disponível em: http://repositorio.ul.pt/bitstream/10451/4884/1/Santos\%20\%282002\%29.pdf Acesso em: 15 jun. 2012.

SOARES, C. S. O. A auto-avaliação em línguas estrangeiras: concepções e práticas dos professores. 2007. 117f. Dissertação (Mestrado em Educação). Instituto de Educação e Psicologia. Universidade do Minho, 2007.

ZABALLA, A. A prática educativa: como ensinar. Porto Alegre: Artes Médicas, 1998. 


\section{ANEXO}

\section{AUTO-AVALIAÇÃO POR CRITÉRIOS - Avaliação individual}

\section{NOME:}

DATA:

Essa modalidade de avaliação visa a oportunizar aos pós-graduandos a olharem para o seu envolvimento no processo desenvolvido na disciplina Formação do Professor de Línguas.

Parte 1: liste no quadro abaixo 4 (quatro critérios) de sua própria escolha, auto atribuindo-se o valor de 0,0 a0,25 a cada um deles, conforme as justificativas a serem apresentadas na parte 2 .

\begin{tabular}{|l|c|c|}
\hline \multicolumn{1}{|c|}{ CRITÉRIOS } & Valor máximo & Valor auto-atribuído \\
\hline & 0,25 & \\
\hline & 0,25 & \\
\hline & 0,25 & \\
\hline TOTAL & 0,25 & \\
\hline
\end{tabular}

Parte 2: Redija um texto, justificando a escolha dos critérios acima e o valor auto atribuído a cada um deles. Sem esse texto a avaliação será considerada incompleta e o valor auto atribuído terá de ser dividido pela metade.

OBS: Entregar a auto-avaliação por critérios juntamente com o quadro das ênfases do processo de apropriação e com o Trabalho Contínuo Criativo (TC). Se preferir poderá enviá-la por e-mail, solicitando confirmação de leitura para evitar desencontros.

\begin{tabular}{|c|c|c|}
\hline & 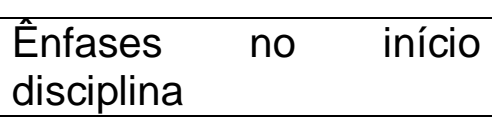 & Ênfases nesse momento \\
\hline $\begin{array}{l}\text { - Nossa! O que é isso? } \\
\text { - É difícil. } \\
\text { - Parece que não é } \\
\text { muito } \\
\text { difícil. } \\
\text { - Está ficando mais fácil. } \\
\text { - Eu já entendo um }\end{array}$ & & \\
\hline
\end{tabular}


Revista InterteXto / ISSN: 1981-0601

v. 6 , n. 1 (2013)

pouco.

- Eu já consigo falar disso. 